\title{
Evaluation of the landslide susceptibility map obtained by a GIS matrix method: a case of Al Hoceima city (northern Morocco)
}

\author{
Taoufik Byou ${ }^{1 *}$ \\ ${ }^{1}$ Department of Geography, FLSH Sais-Fès, route Imouzzar, BP, 59, 30000 Fès, Morocco
}

\begin{abstract}
This work presents a method for preparing landslide susceptibility maps based on an analysis between past movements and predisposing factors. The proposed methodology for determining susceptibility is an adaptation of the matrix method in the territory of the city of Al Hoceima (Northern Morocco). The data needed to evaluate vulnerability has based on the landslide inventory and the available cartographic documents. These data were prepared and integrated into a GIS. This phase of the data preparation has followed by assessment and susceptibility mapping. The obtained map was validated and compared with an independent landslide dataset than the one used to develop the model. The results of the ROC (receiver operating characteristic) curve demonstrate the good predictive ability $(\mathrm{AUC}=0.94)$. We can deduce that the map correlates well with the existing terrain conditions. The successfully validated prediction will enable decision-makers to offer handy information for infrastructure construction and urban planning in the future or other areas with similar situations. Keywords: Matrix method, GIS, landslide susceptibility, Al Hoceima.
\end{abstract}

\section{Introduction}

The landslide susceptibility map constitutes essential to understand and assess the potential risk of landslides for human societies. In the city of Al Hoceima, landslides are an increasing threat to the population, infrastructure, and means of transport. Information on landslide risk has needed in this city, where data is scarce to mitigate the threat generated by this phenomenon. Nowadays, many new approaches to identify and map landslide susceptibility in less developed regions are restricted by insufficient data at places where it is needed most. Given that our study area shares the same problem of missing data, we considered that the matrix assessment approach is applicable to promote the incorporation of information on landslide risks in urban planning [1,2]. This approach allows the production of landslide susceptibility maps providing useful information for urban planning with a minimum of data. It is used by several authors and in different geological contexts $[3,4,5]$. The objective of this work is to carry out a method of mapping and validation of landslide susceptibility map in the city of Al Hoceima, based on the matrix method. This

* Corresponding author: taoufikbyou@gmail.com 
method adopts a statistical analysis of the correlation between the predisposition factors and the inventory to map and assess the landslide susceptibility. The verification of the accuracy of the results is done by the ROC curve by comparing the obtained susceptibility map with the inventory map.

\section{Presentation of the study area}

The city is located north of the province of Al Hoceima, with a surface area of $34 \mathrm{~km} 2$, situated between the latitudes $35.16^{\circ}$ and $35.28^{\circ} \mathrm{N}$ and longitudes $3.87^{\circ}$ and $4.05^{\circ} \mathrm{W}$. It is bounded to the north and east by the Mediterranean (the Alboran Sea and Al Hoceima Bay), to the south by Oued Isli and the west by the tip of Boussicour (fig.1). It is a mountainous region, made up of accentuated reliefs, separated by deep valleys. These mountains have been marked by limestone and dolomitic crests. They reach $300 \mathrm{~m}$ at jebel Malmusi and $406 \mathrm{~m}$ at jebel Monte Palomas, and by high cliffs often going 100-140 m at the level of the dolomitic plateau "Morro nuevo" and Al Hoceima bay [6].

Geologically, this area is part of the Bokkoya chain formed by geological layers superimposed by anomalous contacts and cut by normal faults [7]. The outcropping materials are mainly composed of Devonian and Lias limestones, Triassic Dolomites, EoOligocene marls, Silurian shales, dune sands [8].

The study area has characterized by the Mediterranean, semi-arid climate, marked by hot summers and temperate winters. The average annual rainfall is $385 \mathrm{~mm}$ [6]. The seasonal alternation of the environment associated with the brutality of the rains and the decrease in plant cover aggravates the action of said rains on the soil and often promotes erosion and landslides.



Fig. 1. Location of Al Hoceima: (a) geographical location of the city in Morocco, (b) zoom on the study area. 


\section{Methodology}

The matrix method consists of creating a database integrating the predictive factors and the inventoried landslides (fig. 3). This method is based on the map in the city Al Hoceima at 1: 2000 (2014 edition, Lambert zone 1 projection), which is considered a source of morphological factors such as slope exposure, slope and altitude, and drainage density. The geological map of Al Hoceima (1:50,000) furnished information on lithology and faults. The assessment of the seismic factor has based on the 1:40,000 seismic micro zoning map developed by Abdelouahid Talhaoui in 2004 [9]. The land use data has extracted from the visual interpretation of Google Earth images (2018 edition). to apply this method, all predictive factors are transformed into raster format with cell size equal to $5 \mathrm{~m}$ and reclassified for use in the GIS environment. Afterward, a correlation analysis between the factors is determined, and then all combinations between the classes of these factors are identified using Arcgis software. The next step in developing the landslide susceptibility model is to determine the areas affected by landslides in each combination of the predictive factor classes (Fig. 2), which is called the landslide matrix. In the last step, the percentages of the landslide-affected area in each combination of predictors are calculated $[10,11]$. Thus, the validity of this approach has demonstrated to establish a landslide susceptibility map that predicts the location of new landslides. The ROC curve has been using to validate the map obtained using a dataset of recent landslides independent of the data collected to develop the model $[12,13]$.

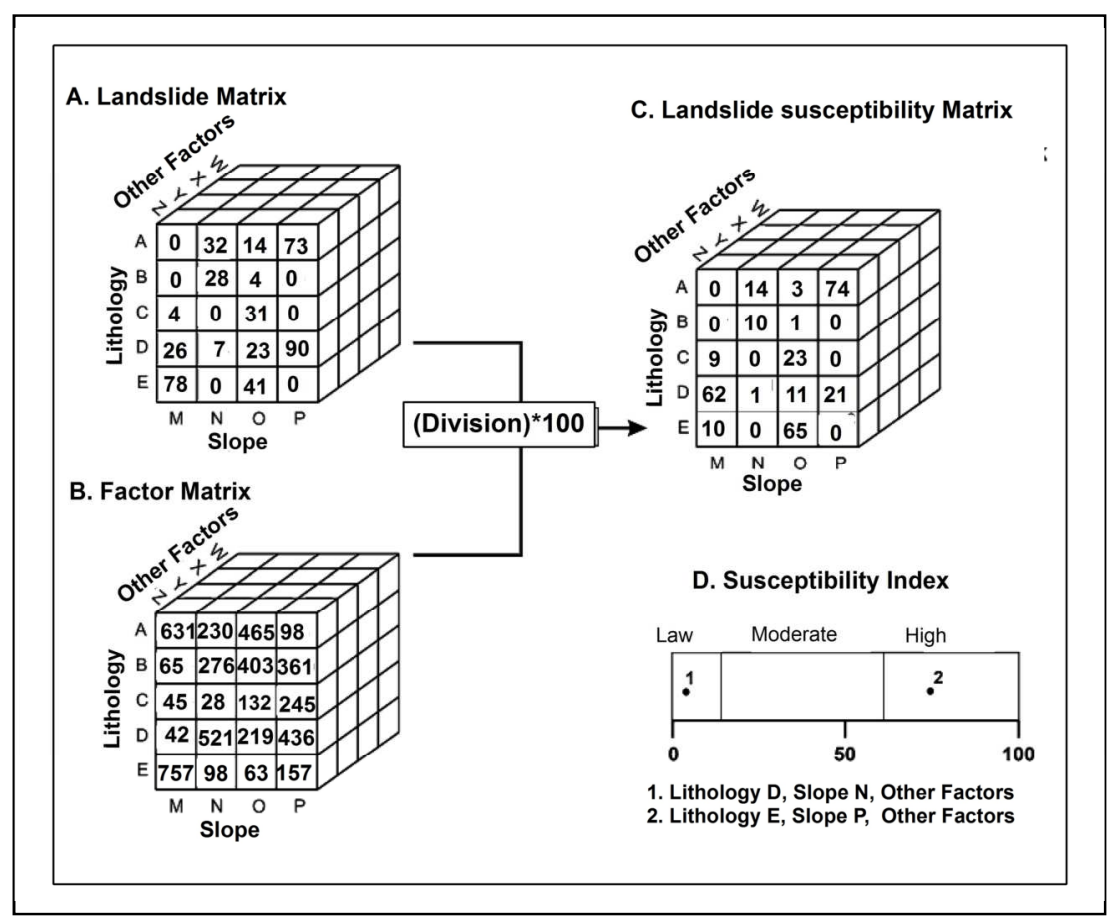

Fig. 2. Diagram illustrating the assessment of landslide susceptibility by the matrix method. In this figure, the predictive factors used are lithology, slope, and other factors. A, B, C, D, M, N, etc., represent the classes of these factors. Mesh represents all combinations of the classes of factors; (A)The number inside the mesh shows the area affected by landslides in each combination; (B) The number inside the mesh shows the total area in each combination; (C) the percentage of landslides in each combination. (D) the results have been classifying into different susceptibility levels. 



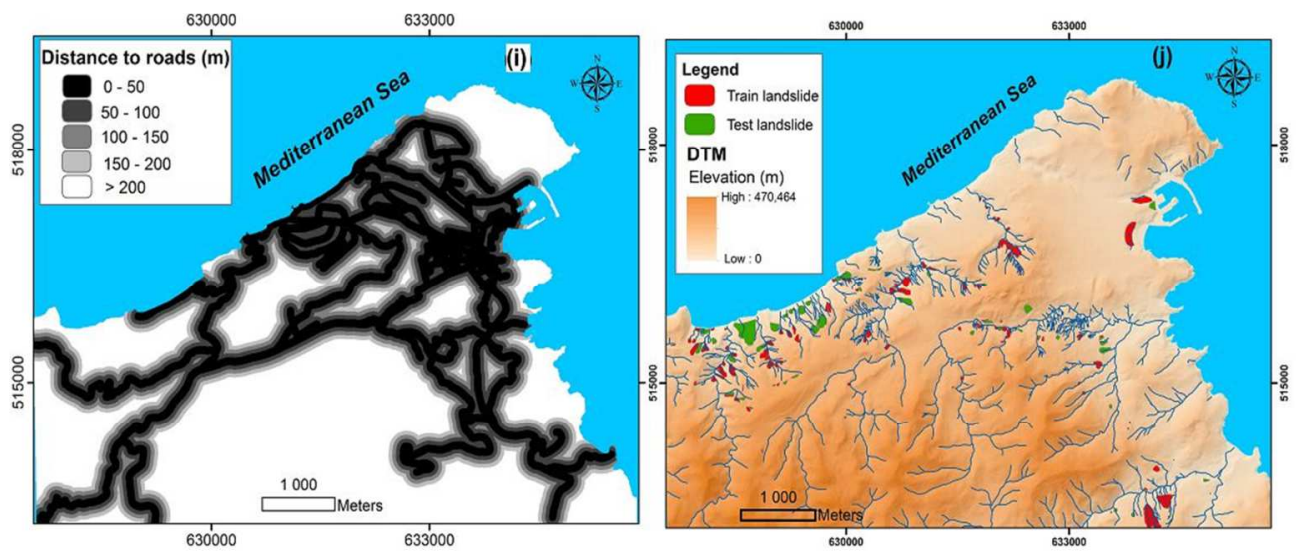

Fig. 3. Maps of the predictive factors: (a) lithology, (b) distance to faults, (c) seismic micro zoning, (d) slopes, (e) Aspect, (f) elevation, (g) drainage density, (h) land use, (i) distance to roads. (j) landslide inventory.

\section{Results}

\subsection{Landslide inventory}

A total of 151 new landslides have been identifying during fieldwork based on geological and geomorphological criteria. Only 45 landslides occurring during 2004-2016, detected from the interpretation of Google Earth images, were reserved for the validation phase (Fig. 3).

\subsection{Analysis of factors contributing to instability}

Factor analysis was done by cross-correlating the predictors and landslides using SPSS software, in which the correlation coefficients have been calculating. Table 1 presents an estimate of the linear correlation coefficient derived from the contingency coefficient. Factors have a significant effect on landslide occurrence where the values of the linear correlation coefficient were higher than $0.4[10,11]$. The results show that landslides have conditioned by lithology, slope, and drainage density. Furthermore, the column "Approximate significance" indicates that the statistical significance value is less than $0.0005(\mathrm{p}<0.0005)$. Therefore, the association between landslides and the predictive factors is statistically significant.

\subsection{Landslide susceptibility modeling}

The modeling has carried out according to the matrix method in an ArcGIS environment. This involved zoning the study area depending on whether the combination of factors that result in each pixel was more or less likely to generate movements. The resulting map is an example of a landslide susceptibility map with four hazard levels (very low, low, moderate, high, very high) determined by the classification of natural breaks (Fig.4). The low susceptibility levels represent $96.15 \%$ of the studied area. If moderate susceptibility has included, this percentage rises to over $98.06 \%$. The areas of high and very high susceptibility represent, respectively, $1.06 \%$ and $0.88 \%$. The comparison between the 
susceptibility map and the inventoried landslides shows that $66.33 \%$ of the landslides have localized in a very high hazard zone, $23.77 \%$ have placed in a high hazard zone, $9.73 \%$ have situated in a medium hazard zone and, $0.17 \%$ have found in a low or no hazard zone (Table 2). These values indicate that the map obtained limits the zones of maximum susceptibility to the only relatively small zone where the combination of factors favoring this phenomenon exists.

Table 1. Estimated correlation coefficients are resulting from the analysis of the predictive factors

\begin{tabular}{|c|c|c|c|}
\hline Predictive factors & $\begin{array}{c}\text { Contingency } \\
\text { coefficient }\end{array}$ & $\begin{array}{c}\text { Significance } \\
\text { approx }\end{array}$ & $\begin{array}{c}\text { Linear correlation } \\
\text { coefficient }\end{array}$ \\
\hline Lithology & 0.165 & 0.000 & 0.483 \\
\hline $\begin{array}{c}\text { Distance to faults } \\
\text { (m) }\end{array}$ & 0.031 & 0.000 & 0.209 \\
\hline Slope $\left(^{\circ}\right)$ & 0.072 & 0.000 & 0.419 \\
\hline Aspect & 0.061 & 0.000 & 0.294 \\
\hline $\begin{array}{c}\text { Elevation (m) } \\
\text { Drainage density } \\
\text { (Km/Km }{ }^{2}\end{array}$ & 0.091 & 0.000 & 0.359 \\
\hline $\begin{array}{c}\text { Seismic } \\
\text { microzoning } \\
\text { (période) }\end{array}$ & 0.024 & 0.000 & 0.490 \\
\hline $\begin{array}{c}\text { land use } \\
\text { Distance to roads } \\
\text { (m) }\end{array}$ & 0.045 & 0.000 & 0.184 \\
\hline
\end{tabular}

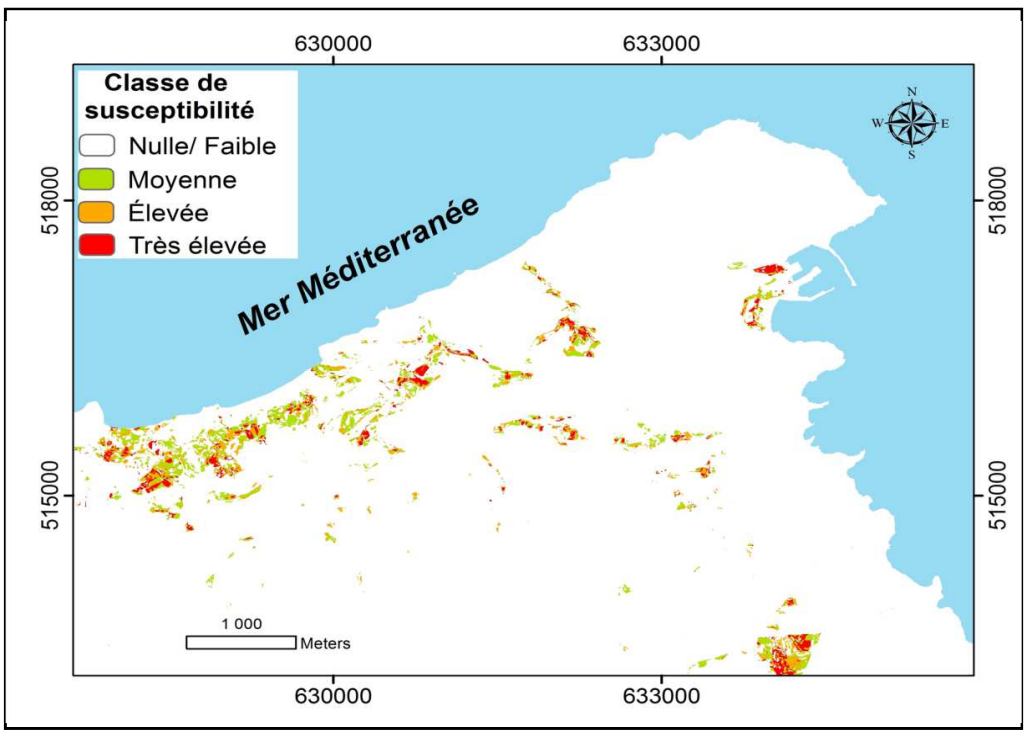

Fig. 4. Landslide susceptibility map 
Table 2. Characteristics of landslide susceptibility classes

\begin{tabular}{|c|c|c|c|}
\hline $\begin{array}{c}\text { Susceptibility } \\
\text { class }\end{array}$ & $\begin{array}{c}\text { Susceptibility } \\
\text { index (\%) }\end{array}$ & $\begin{array}{c}\text { Class } \\
\text { area (\%) }\end{array}$ & $\begin{array}{c}\text { Surfaces of } \\
\text { inventoried } \\
\text { landslides } \\
\text { (\%) }\end{array}$ \\
\hline None/Low & $0-10$ & 96.15 & 0.17 \\
\hline Moderate & $10-36$ & 1.91 & 9.73 \\
\hline High & $36-67$ & 1.06 & 23.77 \\
\hline Very High & $67-100$ & 0.88 & 66.33 \\
\hline
\end{tabular}

\subsection{Validation of results}

Once the susceptibility map has been producing, a validation evaluation of the results must be carrying out. There are several ways to carry out this step: using the landslide inventory dataset to perform both cartography and validation or using an independent dataset of inventoried landslides that are not integrating into the susceptibility analysis. The latter approach has been applying in this work by comparing the locations of 45 recent landslides occurring in 2004-2016 with the susceptibility map [6]. The area under the ROC curve is a valuable indicator to validate the prediction performance of the model $[12,13]$. In this study, it can be seen that the AUC value reaches 0.94, which indicates that the model has an excellent predictive capability (fig. 5).

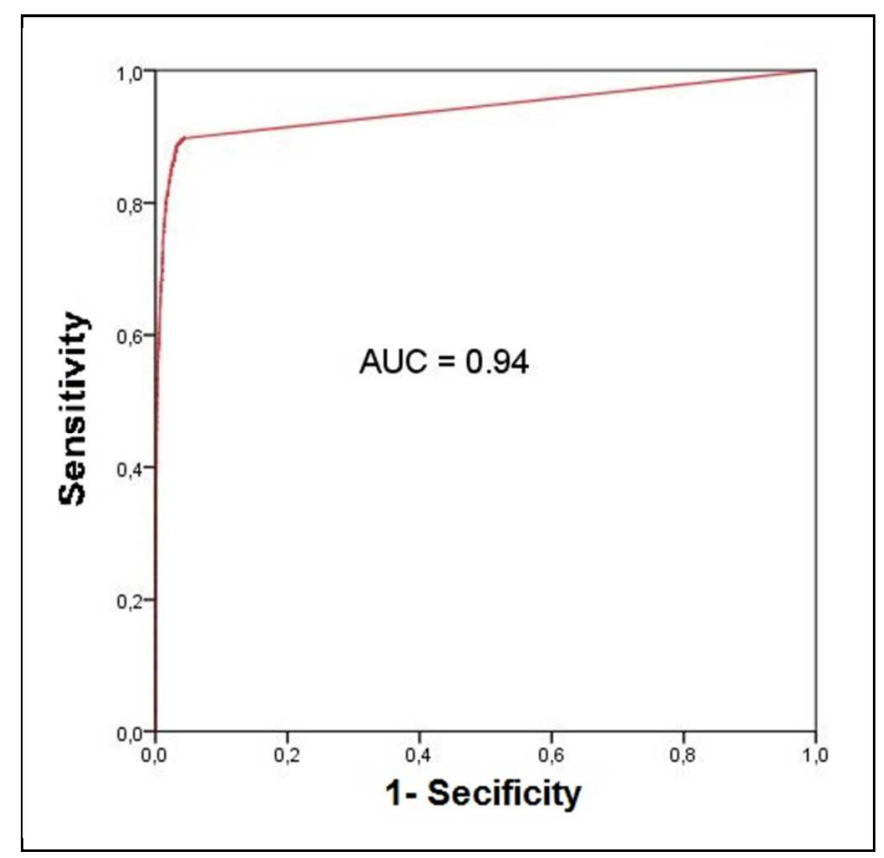

Fig. 5. ROC curve of the susceptibility map 


\section{Discussion and conclusion}

The matrix assessment has been implementing using the predictive factors to establish the landslide susceptibility map for Al Hoceima. It has founded that landslides were more sensitive to three factors: lithology, slope, and drainage density. Thus, identifying areas with different susceptibility to landslides has based on factors impacting the physical activity by which landslides occur. The increasing incidence of landslides with high and very high susceptibility categories indicates that the map produced using this methodology accurately identifies areas of different susceptibility. The statistical test confirms that the results are not due to pure chance, but to determining factors responsible for the occurrence of landslides. Thus, the validity of the matrix evaluation method is confirmed to produce a susceptibility map that predicts the location of new landslides.

The map obtained provides a quantitative representation of the spatial probability of landslides occurrence, which is suitable for urban planning in the city of Al Hoceima and especially in the phase of realization of major public works and the step of execution when adopting appropriate preventive measures.

\section{References}

1. J.V. De Graff, E.E. Brabb, A.P. King, Landslide hazard assessment. In: Primer on natural hazard management in integrated regional development planning. DRDE, General Secretariat, OAS, Washington, DC (1991)

2. J.V. De Graff, H.C. Romesburg, R. Ahmad, Nat Hazards, 64, 729-749 (2012). https://doi.org/10.1007/s11069-012-0267-5

3. R.J. Maharaj, , Engineering Geology, 34(1-2):53-79 (1993). https://doi.org/10.1016/0013-7952(93)90043-C

4. M. Cross, Engineering Geology Special Publications, 15(1), 247-261 (1998). doi:10.1144/gsl.eng.1998.015.01.26

5. T. Fernández, C. Irigaray, R. El Hamdouni,J. Chacón, Natural Hazards, 30, 297-308 (2003).

6. T. Byou, KH. Obda, A. Taous, I. Obda, Geomatica, 75 (1), 1-25, (2020). https://doi.org/10.1139/geomat-2019-0025

7. O. Azzouz, B. El Fellah, A. Chalouan, Bulletin de l'Institut scientifique, 24: 33-40 (2002).

8. K. Marga, A. Abdelgader, Can. Geotech. J. 35(3): 460-470 (1998). https://doi.org/10.1139/cgj-35-3-460

9. A. Talhaoui, M. Aberkan, Iben Brahim, A El Mouraouah, PANGEA, 43/44, 3-18 (2005)

10. F. Irigaray, T. Fernández, R. El Hamdouni, J. Chacón, Nat Hazards 41, 61-79 (2007). https://doi.org/10.1007/s11069-006-9027-8

11. T. Fernández, J Delgado, F.J. Escarcena, J. Pérez, J. Jiménez-Perálvarez, C. Irigaray, R. El Hamdouni, J. Chacón, Methodology for Landslide Susceptibility and Hazard Mapping Using GIS and SDI, Intelligent Systems for Crisis Management. Lecture Notes in Geoinformation and Cartography. Springer, Berlin, Heidelberg, 185-198 (2013). https://doi.org/10.1007/978-3-642-33218-0_14

12. S. Beguería, Nat. Hazards, 37(3): 315-329 (2006). https://doi.org/10.1007/s11069-005$\underline{5182-6}$ 
13. M. Fressard, Les glissements de terrain du Pays d'Auge continental (Normandie, France) Caractérisation, cartographie, analyse spatiale et modélisation, Thèse de doctorat, Université de Caen Basse-Normandie (2013) 